\title{
The Experiences of Adult Learning Centre Educators in Implementing Outcomes-Based Assessment
}

\author{
Tebogo I Mogashoa \\ College of Education, University of South Africa \\ PO Box 392, 0003 Unisa, South Africa \\ Email: mogasti@unisa.ac.za
}

\section{Doi:10.5901/mjss.2013.v4n14p455}

\begin{abstract}
The move from the old curriculum to an outcomes-based education, presented educators with challenges. In outcomes-based education there are learning outcomes that should be attained and educators had to change the way in which they were used to assess their learners. Given the challenges that are associated with outcomes-based assessment, it is important to find out how these challenges are addressed. The main research question is: What are Adult Learning Centre educators' experiences in implementing outcomes-based assessment? A qualitative research paradigm was followed in this study to collect data through interviews and observations. Purposive sampling was used to select information- rich -informants. The sampling involved schools from different socio-economic backgrounds. Data analysis involved identifying similarities and presenting a discussion of the research. Informants' consent was requested for the interviews.
\end{abstract}

Keywords: specific outcomes, assessment criteria, forms of assessment, learning programme, work-schedule, lesson plan.

\section{Introduction and Context of the Study}

There have been critics of the South African education policies by stake holders in education and they have condemned the National Department of Education for a curriculum they say is irrelevant and uninteresting for the majority of the South African learners. Before 1994 the education system in South Africa contradicted world trends by deliberately choosing to serve education needs of only a section of the South African population. The birth of democracy in 1994 led to the establishment of a new education system. The apartheid education system has disadvantaged the majority of South Africans especially the black communities. The new situation demanded serious changes especially in education.

Among other things which were proposed by the Government of National Unity (GNU), was the introduction of outcomes-based education. This ushered in Curriculum 2005 with its emphasis on outcomes-based education. According to Kramer (2006:1), the introduction of outcomes-based education in South African schools and the advent of Curriculum 2005 marked an exciting transformation of the education system. There was consensus about transforming education in South Africa by different stakeholders, hence the introduction of the new curriculum.

The Department of Education has taken a transformative approach by introducing outcomes-based education with emphasis on critical outcomes. Critical outcomes are broad educational goals or a set of skills, attitudes and knowledge that all learners should demonstrate after being exposed to learning and teaching. Curriculum 2005 was also informed by the objectives of the South African Qualifications Authority Act, 1995 (Act 58 of 1995) (RSA,1995:1) which were to create an integrated national framework for learning achievements, to enhance the quality of education and training , to accelerate the redress of the past unfair discrimination, training and employment opportunities and thereby contribute to the full personal development of each learner and the social and economic development of the nation at large. Thus the government introduced a new education system which aimed to cater for all its citizens regardless of race, culture, gender, creed or religion.

However, the changes in education had an impact on the attitudes, morals and performance of educators in general and assessment in particular. These changes required a paradigm shift on the part of educators. The introduction of outcomes-based education made many demands on both the educators and the education system in terms of how learners should be assessed. Educators had to change the way they used to plan and teach while on the other hand learners had to change the way they used to learn. The new curriculum required that educators should be able to understand and respond flexibly to the challenges of the new approaches to curriculum, methods and assessment strategies. 
It was therefore logical and appropriate to revisit the implementation of outcomes-based assessment in Adult Learning Centres. A thorough investigation was done to identify educators' problems in implementing outcomes-based assessment. This formed the basis on which this study was laid. According to Samuels (2009:1), research is designed to solve a particular existing problem so that there is a much larger audience eager to support research that is likely to be profitable or solve problems of immediate concern such as assessment. Based on research, management can make intelligent and informed decisions (Moorty 2010:1). It is for this reason that this research was necessary for education policy makers in realising how teaching and learning is affected by the various education policies especially in regard to assessment. It is hoped that the study will also inform policy makers about problems experienced by educators in the implementation of assessment policies. Probably, policy makers and decision-making bodies will use the outputs of this study in shaping the education system in future. Assessment policy can have a negative impact on teaching and learning if not appropriately implemented, e.g. interpretation of the various assessment criteria. The study will also assist in highlighting educators' opinions, ideas and recommendations in current debates about challenges of interpreting and implementing the various education policies on assessment.

The significance would be to serve as a motivating tool for educators to continue improving and equipping the learners with a variety of skills and competencies so that the set learning outcomes are achieved. Drotar (2007:3), states that in order to be significant, the research needs to exceed the threshold of current scientific work in a specific area. A research study updates previous researches in its development. The significance of the study should discuss the importance of the proposed research and its relevance to the present debates about outcomes-based assessment. The investigation might be relevant for theory, practice and future research. The research study can enhance the critical and analytical thinking of students, therefore, in most of the institutions small research studies are made as essential components of the syllabus. The research study can give food for thought to the new researchers.

Though several studies on various aspects of education have been done, this research will add to what is currently known and unknown about outcomes-based assessment. This study is also considered to be important in the sense that it could create interest among researchers and educators to engage in more critical reflection and debate on the implementation of assessment policies because educators need to have a common understanding of how learners should be assessed. The voices of educators will assist the Department of Education to develop strategies and mechanisms of improving the standard of teaching and learning in schools so that assessment is appropriately implemented. The educators are the key role players through which all aspects of education policies pertaining to teaching and learning, including assessment, reach the learners.

\section{Theoretical Frameworks}

McGregor (2003:1) sees critical discourse analysis as tools to help members of the profession understand the messages they are sending to themselves and others and to understand the meanings of the words spoken and written by others (www.kon.org/archieves/forum/15-1/mcgregorcda.html). Lucke (1996:12), states that critical discourse analysis sets out to generate agency among students, teachers, and others by giving them tools to see how texts represent the social and natural world in particular interests and how texts position them and generate the very relations of institutional power at work in classrooms, staffrooms, and policy. Discourse analysis is a qualitative method that has been adopted and developed by social constructionists and the focus is any form of written or spoken language, such as a newspaper article (www.eamonfulture.com/discourseanalysis.html). Critical Discourse Analysis assisted in investigating educators' knowledge and understanding of outcomes-based assessment. This then developed deeper and richer insights and exposed the researcher and other stakeholders in education to a broad spectrum of literature and knowledge of outcomes-based assessment and proposed how issues and challenges can be overcome and mitigated.

According to Basely (2007: 41), beginning a project by viewing what is already known on the subject is a well established practice, as it reviews the implications of the relevant theories for the topic, and methods others have used to investigate it. Holy, Arhar and Kasten (2005: 263), state that by reviewing literature, we synthesize multiple dimensions of the topic and deepen our understanding of the contents of our own research. According to Terre Blanch (2007:20), refining a research problem involves identifying a theoretical framework upon which to base the research. It is imperative to state the theories that influenced the research problem as well as the research methods that were used. This study was underpinned by a critical discourse analysis theory in which the researcher expressed his comments or judgements based on written or spoken communications, discussions or conversations with educators. It involved an analysis of the merits and demerits of the implementation of outcomes-based assessment. It was for these reasons that critical discourse analysis was used as a framework to engage and converse about the research problem and questions of this 
study.

Critical discourse analysis assisted the researcher in analysing how outcomes-based assessment was affected by the social inequalities in various communities in Adult Learning Centres. Critical discourse analysis involves debating or communicating in either spoken or written form. This means that assessment policies are drafted and people should be given the opportunities to be involved in debates and conversations about these assessment policies and in order to do so valuable data generated through research such as this was critical.

Critical discourse analysis does not provide a tangible answer to problems based on scientific research but it enables access to the ontological and epistemological assumptions behind a project, a statement, a method of research, or a system of classification (www.ischool.utexas.ed-palmquis/courses/discourse.htm). Discussions with participants in this study assisted in revealing motivations behind assessment texts. Teaching and learning processes and activities are either in spoken or written form. Educators should have appropriate knowledge of assessment policies by reading about assessment policies or by listening to experts' descriptions of these assessment policies.

According to Wodak (2009:31), critical means not taking things for granted, opening up complexity, challenging reductionism, dogmatism and dichotonomies, being self reflective in research, and through these processes, making opaque structures of power relations and ideologies manifest (www.qualitative.research.net/fgs/). Assessment policies were appropriately and critically analysed and described to enable their effective implementation in Adult Learning Centres. The principles associated with outcomes-based assessment were asserted. Discourse analysis is a qualitative method that has been adopted and developed by social constructionists and the focus is any form of written or spoken language, such as a newspaper article (www.eamonfulture.com/discourseanalysis.html). The educators explained how they interpret the various policies on assessment.

Apart from critical discourse analysis as the principal theory, this study was also influenced by teaching and learning theories such as constructivism. The focus was on how knowledge or reality is socially constructed. Barbie and Mouton (2007:17), define constructivism as the theory of knowledge or epistemology that argues that humans generate knowledge and meaning from experiences. Knowledge is not fixed but is constructed, shaped and reconstructed in different social contexts and at different times. The way outcomes-based assessment was implemented in Adult Learning Centres needed to be critiqued so as to suggest alternatives to assist the education system of the country. Being critical does not necessarily mean being negative, but critiques can also be positive. Outcomes-based assessment was analysed and interpreted appropriately.

The main research question was as follows:

* What are educators' experiences of implementing outcomes-based assessment?

\section{Research Design and Methods}

The research methodology of this study was qualitative and inductively based. Qualitative method was used to gather information from the different categories of participants on how outcomes-based assessment was implemented.

The advantage of this approach is that it provided rich descriptive data as observed by the researcher during the interactions with participants. This method enabled the researcher to capture different experiences of the participants accurately. According to Mugo (2011:5), a population is a group of individuals, persons, objects, or items from which samples are taken for measurements, for example a population of presidents or professors, books or students. Selection of the Adult Learning Centres was based on the following criteria:

- The type of Adult Learning Centres,

- The educator population and

- The location of Adult Learning Centres.

The target group and population of the study comprised of experienced educators who are teaching level 4 learners, English as First Additional Language (FAL). Three Adult Learning Centres in Kwa Mhlanga circuit of Mpumalanga Department of Education were selected to participate in the study. Each Adult Learning Centre had three participants. Adult Learning Centres were selected purposefully as they were regarded as rich informants of knowledge the research intended to gather (Patton, 1990:47).

\section{Data Collection}

Data was collected through observing and describing what are the experiences of the participants in implementing outcomes-based assessment. The researcher interacted with the participants in order to get the most reliable information 
about outcomes-based assessment. To avoid discrimination, the researcher gave the participants equal opportunities to participate in the investigation. The researcher used focus group interviews and individual interviews to collect data. Follow-up sessions were conducted in the form of structured and unstructured interviews. Focus group interviewing is a carefully planned discussion designed to obtain perceptions on a defined area of interest in a permissive non-threatening environment (Krueger and Cacy 2009:6). This data collection method is actually an open group discussion. The format of this type of group interview is not that of question and answer. The researcher encouraged respondents to use their own terminology in describing their experiences of implementing outcomes-based assessment. The reason for this was to allow the data to truly emerge from the respondents.

The researcher spent sufficient time with the participants and observed persistently in order to ascertain validity of information as well as by triangulation, which is, using more than one method of data collection. To ensure that reliability and validity were assured in this study, the researcher first pilot-tested the research instruments and used opinions from experts.

\section{Data Analysis and Interpretation}

Data analysis and interpretation involved the analysis and interpretation of documents related to outcomes-based assessment. Data was analysed by selecting, comparing, synthesising and interpreting information to provide explanations. The researcher analysed and interpreted what is the "big picture" of what the participants said and how individual statements from the participants related to what the "big picture" stands for. The researcher used the inductive approach to ensure that the research findings emerge from the frequent, dominant or significant themes inherent in raw data generated. Comparisons were drawn, similarities identified and a discussion of the research presented. Once the data have been generated, the researcher organised the data and discovered the relationships or patterns through close scrutiny of the data. The data was coded, categorised and condensed. The researcher then interpreted and drew meaning from the displayed data. The first step to be taken by the researcher involved data organisation. The process also involved grouping of information, coding information of similar kind and genre. After major topics and sub-topics from the interviews and document analyses have been identified, data collected was categorised according to the topics and sub-topics.

\section{Research Findings and Discussions}

\section{1 "What is your general understanding of outcomes-based education and outcomes-based assessment?"}

In responding to the question above, one educator said, "It is a continuous process whereby teaching takes place all the time". Another participant indicated that in outcomes-based education, "concepts are integrated and the teaching is learner-centred". One of the educators stated that in outcomes-based education, "learners are given opportunities to learn at their own pace". Some educators added that "there is activity-based learning, group work and learners are active participants in the learning process".

None of the educators referred to outcomes-based education according to Spady's definition that outcomes are clear results that have to be demonstrated at the end of significant learning experiences and are performances that embody and reflect learner competence in using content, information, ideas and tools successfully. However, educators expressed a very practical view about what constitutes outcomes-based education. Educators' understanding of outcomes-based education reflects terminology and some basic concepts used in learning area statements and assessment policies. Based on the literature study and educators' responses, one could conclude that they have a fairly good understanding of what constitutes outcomes-based education.

\section{2 "What are the challenges you experience with outcomes-based education and outcomes-based assessment?"}

Most educators conceded that they encountered problems in developing the learning programmes. One of the educator said, "It is very difficult to differentiate between context and content and every time we attend a workshop the departmental officials come with different versions about these concepts." This was a similar view expressed by another educator who said, "One curriculum implementer said that content is found in the context while the other one put it viceversa." Educators held the view that the education department should develop a common learning programme for all the Adult Learning Centres for the circuit. 
Most educators conceded that they find it difficult to analyse and integrate assessment criteria into a work schedule. A few of the verbatim responses are indicated below:

\section{"Assessment criteria are so complicated and one finds it difficult to identify what is content in them. Specific outcomes} are clear but integration is difficult."

"We read through these assessment criteria but one always finds it difficult to come up with a clear interpretation." Another participant expressed his confidence in identifying the content in the assessment criteria by saying, "You must identify what are skills, knowledge and values so that you can decide what the content in these assessment criteria is." They held the view that the template for the work schedule should be simplified because it is not easy for them to interpret.

Most educators held the view that some concepts of a lesson plan are not easy to interpret. This view was evident when one of the educators who participated in this study said, "The concepts of looking forward to and looking backward at in the lesson plan are really not easy to be accomplished. I always don't know what to write in that column. I have asked for clarity in this regard, but I always don't have a clear answer."

Some educators complained that a lesson plan template is so complicated with concepts that they cannot interpret. One participant said, "Some of the concepts like planned assessment and assessment activities in the lesson plan are confusing. I don't see any difference because assessment activities are just the same as planned assessment. This is just a repetition of the same information and creates more work for us." All educators held the view that the template for the lesson plan should be simplified.

The interviews revealed educators' concerns in terms of the volume of paper work involved in planning and assessment procedures. Educators indicated that there are so many assessment criteria they have to assess learners against. One educator responded by saying, "I am teaching four learning areas and I am expected to do planning in all of them and record assessment. This takes too much time and I end up not teaching learners but busy planning." Another educator expressed similar views by stating, "I must assess learners in all the five learning areas and the large numbers in each class makes it very difficult. When I have to record assessment, it takes me the whole day. This is too much work for us." However, the documents analysed revealed a systematic and consistent recording of learner achievement and progress.

The level 4 educators conceded that outcomes-based assessment confused them and had initially caused them frustration and anxiety. Inadequate educator preparation for the implementation of outcomes-based assessment was expressed by one educator when she said, "The manner in which we were trained is not adequate. We were trained for only a week and we are expected to deliver the goods. There are not enough resources to make implementation easier. This is only easy in schools in towns because they have resources." This was a similar view held by another participant who said, "The people who were conducting workshops were also not clear about some of the aspects of outcomesbased assessment." All educators interviewed held the view that the quality of educator development in terms of the implementation of outcomes-based assessment was poorly planned.

Though educators who were interviewed indicated that they attended workshops on the implementation of outcomes-based assessment, they conceded that a week was inadequate and too basic. One educator said, "We were given superficial training on outcomes-based assessment." This was supported by another educator who said, "The training programme was based more on theory than on practice. We were not given practical examples of implementing outcomes-based assessment in a real classroom situation." This was the response from another educator, "I was very disappointed when facilitators gave different versions of what the difference is between content and context."

Most educators interviewed were not clear about the principles of assessment. Amongst the responses from those interviewed were the following:

"Assessment is outcomes-based and learners learn independently."

"Assessment is outcomes-based and learners can design their own activities and learn at their own pace."

"Assessment is continuous and learners do not write tests or examinations."

Based on the above responses it was clear that educators do not have a clear understanding of the principles of assessment because no one has made reference to the principles of assessment as outlined in the assessment policy document.

Educators were not clear in their responses with reference to the principles of recording and reporting. A few of the verbatim responses are indicated below: 
"I only know that everything learners do in class should be recorded. Reporting is done at the end of the term to show learners' achievement."

"Reporting is done to show learner progress and achievement. Reporting is done at the end of each term to inform learners of what they have achieved and what they have not achieved."

From the above responses, it was clear that educators had a very simplistic understanding of the principles of recording and reporting. None of the educators made reference to principles of recording and reporting as outlined in the National Protocol on Assessment.

Educators complained about lack of resources, both material and human. These were the responses from the educators who were interviewed: One educator said, "We don't have textbooks that clearly outline the specific outcomes and assessment criteria. We still rely on the old textbooks that we were using." Another educator also held the similar view when he said, "If the department of education can supply appropriate textbooks that outline these specific outcomes and assessment criteria as well as the assessment activities that will assist us in implementing outcomes-based assessment. The textbooks that we are using are not appropriate."

From the educators' responses, it was clear that educators had difficulties in developing learning activities that are appropriate to the various specific outcomes. These were some of the responses from the educators who were interviewed:

"I struggle to create an activity for learners which will assist them to achieve the specific outcomes."

"In our workshops we are not actually assisted on how to develop learning activities that are informed by these specific outcomes."

With regard to outcomes-based assessment, educators conceded that forms of assessment are commonly used in ABET level 4. Educators also expressed a common view of equating continuous assessment with outcomes-based assessment. Reference was also made to assessing specific outcomes and assessment criteria. Some educators also made reference to assessment methods such as peer assessment, self-assessment, group assessment, but they put more emphasis on educator assessment. Educators also made mention of forms of assessment in languages such as creative writing, response to text, functional writing and investigation. Most educators expressed their positive views about baseline assessment and that if appropriately applied, it could assist them to determine what learners already know. However, the educators agreed that they usually do not apply baseline assessment. Some of those who were interviewed like one of the educators said, "Baseline assessment can assist me to plan learning programmes and learning activities." Another educator also shared the same view when she said, "Baseline assessment can assist if it is done at the beginning of each task, grade or phase. This is the same as the old approach when we spoke of testing of prior knowledge. However, we don't usually apply baseline assessment."

Educators had different views about diagnostic assessment. This is how they expressed their views: one educator said, "I think as educators we don't have the necessary skills to apply this kind of assessment." Another educator expressed a different view when he said, "Diagnostic assessment is essential because it assists us to plan assessment activities in a way that even learners who experience barriers to learning are taken into consideration." One of the participants expressed her view in this way, "Learners who experience barriers to learning should be send to special schools." From the educators' responses it can be deduced that much needs to be done to make sure that learning and teaching is consistent with outcomes-based education philosophy of inclusivity in education.

When responding to how formative assessment can assist in giving feedback to learners and about learner performance, educators had similar views. One educator said, "Learners' performance can be recorded and reported to learners. Learners can be assessed orally, with class work and tests." Another educator expressed similar view by saying, "Learners should be involved in various learning activities and tasks. What learners are doing in class can be formally recorded and tests given." Most educators expressed the view that tests are still important but should form part of continuous assessment. With regard to summative assessment, the educators held the same view that this type of assessment gives an overall picture of learners' progress at a given time. These were some of the responses:

"Learners should be given tests at the end of each term so that progress can be monitored."

"Though learners are assessed continuously, it is important to assess them with many tasks at the end of the year. This will assist us in determining whether specific outcomes have been achieved."

From the educators' views, it is clear that learners are assessed through tests at the end of each term and examinations at the end of the year. However educators have indicated that the examination is not the only factor to 
determine whether learners progress to the next level or not.

Most educators conceded that learners learn differently, and this is why they are grouped according to ability levels. One participant said, "I group my learners according to abilities so that I can assist them differently. I do remediation at the end of the day while other groups continue with other activities independently." Another educator expressed her view as follows, "When learners are grouped according to their ability levels, it gives me an opportunity to attend to learners individually." From these views it shows that educators care and are aware of learners' ability levels and provision is made for them. This is in accordance with the outcomes-based principle that learners learn at a different pace and have different learning styles and therefore may not be assessed at the same time, context and in the same way. Educators should apply different methods, tools and techniques when assessing learners because every learner is unique. The interview also revealed that educators used worksheets, tests and projects for self and peer assessment.

With regard to assessing specific outcomes and assessment criteria, most educators expressed the view that they were still assessing against forms of assessment rather than against specific outcomes. These were some of their responses:

"I assess against forms of assessment such as creative writing and response to text."

"I assess learners' progress or achievement against forms of assessment like projects and functional writing."

When asked to submit documents they used as guidelines for outcomes-based assessment, most educators referred to departmental guidelines, policies and workshop handouts. The educators complained that in their workshops they received contradicting documents. One educator said, "I am responsible for different learning areas and we always get contradicting documents when attending workshops on assessment." On the basis of the responses from the educators as well as an analysis of the documents, one can deduce that educators were not familiar with the documents on outcomes-based assessment.

When asked about portfolio assessment, educators indicated that portfolio requirements were consistent with the requirements stipulated by the ABET Learning Centres' policy on assessment. One educator said: "Portfolio assessment includes tests, projects, assignments and worksheets chosen by the learners themselves. The school's policy on assessment highlights some requirements such as managing and accessibility of a portfolio." Another Educator said: "Learners should select evidence to be placed in their portfolios. A checklist should be used by both learners and educators to establish whether the portfolio has been kept according to given criteria." The other educator confirmed that, "Learners' portfolio checklists should have important aspects such as organization and structure, learners' names, grade, date, forms of assessment, index, title page and number of activities." A random analysis of learner portfolios indicated contents that were in line with policy requirements, that is, portfolio should be built over a period of time and retained as proof of the development and improvement of learner achievement.

With regard to the recording of learner's progress, educators indicated that they have records of each learner's progress. This is the response from one of the educators: "We have recording sheets that we designed. We use these recording sheets to record learners' progress." Another educator said: "Some of the curriculum implementers gave us recording sheets, but we are not forced to use them. They only serve as guidelines". This is the response from another educator, "We record anything that we are assessing. We spend more time on assessing learners than teaching them." A critical analysis of the recording sheets used by educators showed that most of them recorded marks for tests. Only a few educators recorded against forms of assessment and specific outcomes.

Educators indicated that the reporting of learners' progress is done by means of written reports. These report cards are sent to learners. This is the response from one of the educators: "We send report cards to learners at the end of each term". An analysis of the report cards showed that not much was said about the specific outcomes and assessment criteria. The report cards showed forms of assessment and the levels of achievement. Educators who were interviewed expressed lack of support in terms of curriculum management. One educator said: "The management team is not fully supporting us on how to implement this outcomes-based assessment. We don't get clear information especially on how to assess learners." This view was also expressed by another educator when she said: "We encounter problems when departmental officials come for moderation. There are no proper guidelines of what is expected of us." According to the responses made by the educators, curriculum management was still a serious challenge at Adult Learning Centres. Most of the educators complained that the management teams do not attend workshops on curriculum matters.

Educators indicated that they do not meet regularly to discuss curriculum matters. They conceded that they only come together when developing learning programmes and do not usually share ideas on how to implement this outcomes-based assessment. One of the educators said: "We don't get opportunities to share and air our views in terms 
of the implementation of this outcomes-based assessment. We are only being informed and expected to implement. We should be given opportunities to participate in curriculum development." Another educator expressed his view when he said, "There is lack of team work on the part of the educators. We don't plan together. Everyone does things the way he or she understands." The interviews revealed that educators and management teams do not promote team work.

\section{Conclusions and Recommendatios}

The introduction of outcomes-based education was the critical turning point of curriculum transformation in South Africa. The introduction of outcomes-based assessment had a negative impact on teaching and learning practices as well as the way assessment was done. The educators did not receive adequate and appropriate training for them to be able to implement the new curriculum. There were inadequate resources to make the implementation of outcomes-based assessment a success. Most educators lacked appropriate knowledge and skills in developing learning activities as required by the principles of outcomes-based education. Document analysis also revealed educators' inabilities in developing learning programmes, work schedules and lesson plans. Recording of learner achievement was done against forms of assessment instead of against specific outcomes and their assessment criteria.

Educators should be provided with in-service programmes which can assist them to explore and develop new ideas to make implementation of outcomes-based assessment easy. Continuous professional educator development should be put in place to assist the educators to cope with new changes of the curriculum. Educators should be given clear content to teach their learners. Guidelines for designing learning and assessment activities should be developed. Educators should be developed on how to assess and record learners' achievement of particular specific outcomes and the assessment criteria. Given the inadequate training, lack of appropriate teaching and learner support materials and the complexity of outcomes-based assessment, it would be useful to investigate the skills, knowledge and values that learners acquire when using outcomes-based assessment approach.

\section{References}

Barbie, E. and Mouton, J. (2006). Research methodology by numbers- a teaching tool. Durban University of Technology. Bazely, P. (2007). Qualitative data analysis with Nvivo. London: Sage Publications.

Drotor, D. (2007), Thoughts on Establishing Research Significance and Preserving Scientific Integrity.

Holly, M.L.; Arhar, J.M and Kasten, C.W. (2005). Action Research for teachers: Travelling the yellow Brick Road (2nd edition) New Jersey: Pearson Prentice Hall.

Kramer, D. (2006). OBE teaching toolkit: OBE strategies, tools and techniques for implementing C2005.

Krueger, R.A. \& Casey, J. (2009). Successful focus groups: practical guidelines for research (4th edition). Thousand Oaks, CA: Sage.

Locke, T. (2004). Critical Discourse Analysis. London: Cromwell Press

Lucke, A. (1996). Text and Discourse Analysis. New York: American Educational Research Association.

McGregor, S.L.T. (2010). Critical Discourse Analysis: A Primer. Halifax. Mount Saint Vincent University

Moorty, S. (2010). The Significance of research in Business Decision Making. Longman. London and New York.

Mugo, F.W. (2011). Sampling in Research. Thoasand Oaks: Sage Publications

Samuels, P. (2009). The importance of research- Why we do research. New Jersey: Prentice-Hall. Inc.

Terre Blanche, (2008). Research in Practice: Applied methods for the social sciences. Juda Academy.

Van Dijk, T.A. (2001). Critical Discourse Analysis: Sage Publications.

Wodak, R \& Meyer, M. (2009). Methods of Critical Discourse Analysis. Longman. London and New York

www.eamonfulcher.com/discourseanalysis.html .

www.ischool.utexas.ed-palmquis/courses/discourse.htm

www.kon.org/archieves/forum/15-1/mcgregorcda.html

www.qualitative.research.net/fgs/ 